Int. J. Plant Sci. 170(5):575-583. 2009.

(c) 2009 by The University of Chicago. All rights reserved.

1058-5893/2009/17005-0002\$15.00 DOI: $10.1086 / 597781$

\title{
SEX-SPECIFIC TRADE-OFFS AND RESPONSES TO FOLIAR SHADE IN THE GYNODIOECIOUS SPECIES SILENE VULGARIS (CARYOPHYLLACEAE)
}

\author{
Amy B. Dykstra,* Marcus T. Brock, ${ }^{1, *}$ Lynda F. Delph, $†$ and Cynthia Weinig ${ }^{1,2, *}$ \\ *Department of Plant Biology, 250 Biological Sciences Center, University of Minnesota, 1445 Gortner Avenue, St. Paul, Minnesota 55108, \\ U.S.A.; and tDepartment of Biology, 1001 East Third Street, Indiana University, Bloomington, Indiana 47405, U.S.A.
}

\begin{abstract}
Allocation trade-offs are predicted to affect evolutionary dynamics, including the evolution of sexual dimorphism. In gynodioecious species, where populations have both females and hermaphrodites, selection may result in sexual dimorphism in individual traits or trait correlations because, in contrast to females, hermaphrodites acquire fitness through both male and female function. Using the gynodioecious species Silene vulgaris, we measured reproductive traits (ovule number, ovule size, anther size, and floral traits related to display) and a vegetative trait (internode length) among plants growing under full sun and foliar shade treatments. We tested for sex-specific correlation structures as well as trait plasticity and the sensitivity of correlation structures to the light environment. Hermaphrodites exhibited a fixed trade-off between anther size and ovule size, whereas females exhibited an ovule size-number trade-off. For a few traits, we detected plasticity to light treatment and plasticity that differed significantly between sexes across light treatments. Exposure to foliar shade resulted in a sex-specific trade-off between vegetative and reproductive allocation; hermaphrodites exhibited a negative correlation (trade-off) between internode elongation and ovule number, whereas females showed a marginally significant, positive correlation between these two traits. The tradeoffs observed in hermaphrodites are of particular evolutionary relevance, suggesting that hermaphrodites will evolve to become increasingly male and populations increasingly sexually dimorphic.
\end{abstract}

Keywords: gynodioecy, phenotypic correlations, plasticity, sexual dimorphism.

\section{Introduction}

In many species, the expression of diverse traits varies systematically across sexes. Aside from differences in the expression of individual traits, selection may result in gender-specific correlations among functionally related traits, that is, among traits that specifically enhance either male or female function. Responses to selection may, alternatively, result in the expression of trade-offs, where increased allocation to one function comes at the cost of allocation to a second competing function. For instance, in gynodioecious plant species, where hermaphroditic and female individuals coexist within populations, hermaphrodites are expected to experience selection to increase male function (Charlesworth and Charlesworth 1978), and increases in allocation to male gametes might come at the cost of female gamete number or quality (Ashman 2003). Such tradeoffs could enhance sexual dimorphism by rendering hermaphrodites increasingly male. However, trade-offs have proved notoriously difficult to detect because of the confounding effects of vigor; large hermaphrodites might produce a large number of both pollen and ovules relative to smaller ones, thereby generating a positive correlation between gamete types (Hillesheim and Stearns 1992). The expression of trade-offs often becomes more evident as environmental quality decreases and all individuals are reduced in size (Stearns 1992). Here, we evaluate

\footnotetext{
${ }^{1}$ Current address: Department of Botany, 3165, 1000 East University Avenue, University of Wyoming, Laramie, Wyoming 82071, U.S.A.

2 Author for correspondence; e-mail: cweinig@uwyo.edu.
}

Manuscript received September 2008; revised manuscript received January 2009. sexual dimorphism and the structure of phenotypic correlations among floral traits and between floral and vegetative traits in the gynodioecious species Silene vulgaris. We also test the sensitivity of individual traits and correlation structures to varying environments.

In gynodioecious species such as $S$. vulgaris with nuclearcytoplasmic control of sex, a cytoplasmic male-sterility mutation invades a population, producing individuals that are functionally female. Hermaphrodites then contribute all of the male gametes to the population, acquire more of their fitness through male compared with female function, and, as mentioned, experience selection to increase allocation to male gametes (Charlesworth and Charlesworth 1978; Delph and Lloyd 1991; Delph and Wolf 2005). A further consequence of this breeding system is that hermaphrodites are likely to experience differing selection pressures on flowers relative to females (Ashman and Penet 2007). If more pollinator visits are required to disperse pollen than to receive pollen, then hermaphrodites may experience selection to increase floral display by way of either flower number or flower size, and in fact, hermaphrodites have been found to produce more, larger flowers than females in many species (see reviews in Delph 1996; Eckhart 1999; Shykoff et al. 2003). Although the between-morph difference in flower size may be caused by many factors (Delph 1996), larger petal size has been shown to increase the dissemination of pollen in hermaphrodites (Ashman and Diefenderfer 2001); that is, sexual selection can contribute to the evolution of sexual dimorphism in gynodioecious species (Delph and Ashman 2006).

In addition to selection possibly operating on single traits differently in hermaphrodites than in females, morph-specific se- 
lection may differentially shape correlations among functionally related traits (also referred to as phenotypic integration; Pigliucci 2003). If this occurs, hermaphrodites may be likely to exhibit high positive correlations among floral trait combinations that affect the efficiency of pollen removal (Conner and Via 1993; Conner and Sterling 1995) and may therefore exhibit stronger floral trait correlations than females. Aside from correlations resulting from increasing functional integration, selection may also result in the expression of negative correlations, or tradeoffs. As alluded to earlier, selection for increased allocation to male function in hermaphrodites may be negatively correlated with allocation to female function; for example, one might predict that increased allocation to display or to male gametes could result in reduced allocation to female gametes.

Sexual dimorphism and the expression of trait correlations, including trade-offs, may be modulated by environmental factors such as resource availability. Many plants respond to environmental cues and plastically alter allocation to vegetative and reproductive structures. For instance, as density increases, plants experience a predictable decrease in irradiance as a consequence of shading by neighbors (Smith 1982, 2000). In addition, plants grown at high density experience a predictable reduction in the ratio of red to far-red wavelengths ( $\mathrm{R}: \mathrm{FR})$ as a result of selective absorption of red light by chlorophyll (Morgan and Smith 1979; Ballaré et al. 1990). This shift in light quality elicits a variety of well-characterized plastic responses known as shade avoidance, which includes increased stem and petiole elongation and accelerated flowering phenology. Allocation to stem elongation is known to reduce leaf and root mass (Maliakal et al. 1999; Weinig 2000), but few studies have tested the effects of variable R : FR on either the expression of sexual dimorphism or potential allocation trade-offs between shade avoidance and reproductive traits (Brock and Weinig 2007). One possibility is that allocation to stem elongation will further reduce allocation to female function in hermaphrodites, whereas female function should be preserved among female plants.

We evaluated whether sexual dimorphism exists in floral traits, floral trait integration, allocation trade-offs, and plastic responses in $S$. vulgaris under foliar shade and full sunlight regimes. Our study addressed the following questions: (1) Is there sexual dimorphism in the average expression of floral traits or in plasticity of floral or vegetative morphology to light treatments? (2) Do phenotypic correlations among floral traits related to display differ between hermaphrodites and females? (3) Do hermaphrodites exhibit fixed or environment-specific tradeoffs between allocation to male and female function? (4) Do females (or hermaphrodites) exhibit the classic life-history tradeoff between size and number for ovules either on average across environments or under light-limited conditions? (5) Do the sexes exhibit similar trade-offs between vegetative and reproductive traits? Taken together, the larger issue inherent to these specific questions is whether sexual dimorphism in environmental responses affects the expression of trade-offs.

\section{Material and Methods}

Silene vulgaris is a gynodioecious perennial native to Europe but naturalized across much of northeastern and north-central North America. Populations occur in disturbed sites and along roadsides, and plants experience variable levels of $\mathrm{R}$ : FR as a consequence of heterogeneous competition with other species common to disturbed areas. Females can be easily distinguished from hermaphrodites, since the pistillate flowers produced by females have only vestigial stamens that lack pollen production, whereas hermaphrodites produce perfect flowers containing 10 pollen-filled anthers (Dulberger and Horovitz 1984; Olson et al. 2005).

Seeds of $S$. vulgaris were collected from $\sim 10-15$ randomly selected hermaphrodites and an equal number of female plants from each of four populations around Mountain Lake Biological Station (Giles County, VA). Seeds were then pooled by sex. Seeds from both hermaphrodites and females from each population were planted in $9-\mathrm{cm}^{2}$ square plastic pots. Of the planted seeds ( $n=48$ per population), half had been produced by hermaphrodites and half by females. Germinated seedlings were randomly assigned to one of two light treatments established in a greenhouse at the University of Minnesota in June 2006. Plants were placed in their assigned light treatment on the day of bolting, which was defined as the appearance of floral buds differentiated from the apical meristem. For the foliar shade treatment, plants were placed under laminated sheets of green theatrical filters (Liberty Green 730; LEE Filters, Burbank, CA) supported by frames constructed with PVC pipe. Plants in the full sun treatment were placed under clear laminate, supported by the same type of PVC pipe frame. Because the green filters used in the foliar shade treatment preferentially absorb red relative to far-red light, the two light treatments differed in both light quality (R : FR; 1.0-1.2 in full sun; 0.6-0.65 in foliar shade) as well as quantity (total irradiance; ambient in full sun; $60 \%$ of ambient in foliar shade).

At anthesis, each plant was visually scored for sex, and hermaphrodites were defined as those plants with well-developed, pollen-producing anthers. The inflorescence of $S$. vulgaris is a compound dichasium, producing a terminal flower and two lateral branches. Each lateral branch proceeds to develop a terminal flower and two lateral branches, and so on. One of the four terminal flowers at the third bifurcation level was collected, $\sim 2 \mathrm{~d}$ after opening, with the aim of collecting each flower when its corolla was fully expanded and before the petals began to wilt. Flowers of $S$. vulgaris have a compound ovary consisting of three locules, each of which is served by a separate style. For each collected flower, corolla diameter and calyx length were measured, using digital calipers. Collected flowers were then preserved in $70 \%$ alcohol. The preserved flowers were dissected and photographed at $\times 10$ and $\times 20$ magnification, using a Nikon SMZ800 zoom stereomicroscope. The digital images were processed with ImageJ, a public domain image analysis program created at the National Institutes of Health (http://rsb.info.nih.gov/ij/index .html). The following traits were measured: petal claw length (the proximate portion of the petal encased within the calyx tube), filament length, anther length, ovary width, and ovule size (two-dimensional area in $\mathrm{mm}^{2}$ ). In addition, the number of ovules in one locule was counted as flowers were dissected. The sex of each plant was confirmed in the photographs by observation of the anthers.

After flower collection, plants were left to flower and develop fruits in the light treatments and were harvested between October 19 and October 26, 2006. The length of the first two internodes (which develop before branching of the inflorescence) 
was recorded, and the total number of flowers produced by each plant was counted and recorded.

We performed mixed-model ANOVA (PROC GLM, SAS ver. 8.02 ) to test for site (random factor), treatment, sex, site $\times$ treatment (random factor), and sex $\times$ treatment effects on the following traits: flower number, calyx length, petal claw length, corolla diameter, filament length, anther length, ovary width, ovules per locule, ovule size, and length at internode 2. Site and site $\times$ treatment effects were nonsignificant; therefore, these terms were pooled with the error. To control for multiple tests on these potentially correlated traits, we performed a MANOVA (PROC GLM, SAS ver. 8.02) on all traits to determine whether there were significant effects of the fixed factors (sex, treatment, and sex $\times$ treatment) that would warrant further univariate testing with ANOVA. Transformations of the data were performed as needed to meet the assumptions of ANOVA. The outcome of significance tests did not differ for transformed and untransformed data for any trait, with the exception of flower number. Therefore, we report results from analyses with untransformed data for all traits, with the exception of flower number, where analyses were performed on log-transformed data. Because of low germination rates and a low level of plant mortality, final sample sizes were reduced for females (11 and 26) and hermaphrodites (20 and 34) in full sun and foliar shade treatments, respectively.

Variance-covariance matrices based on phenotypic values were constructed to test for differences in $\mathbf{P}$ matrices between the sexes as well as whether the sexes might differ in matrix sensitivity to the simulated foliar shade treatment. A reproductive allocation matrix, including anther length, ovule size, and ovule number, was used to evaluate whether hermaphrodites exhibit a trade-off in allocation to male versus female function and whether either sex exhibits a trade-off in ovule size and number. A display matrix, including flower number, calyx length, petal claw length, corolla diameter, and filament length, tested whether hermaphrodites and females differ in floral display. Finally, a vegetative and reproductive matrix, including length at internode 2, anther length, ovule number, and ovule size, evaluated whether plants exhibited a trade-off between vegetative and reproductive allocation across not only the two sexes but also the sexes across light treatments. Because of the low sample size, the matrix of trait (co)variances for females in full sun was dropped from the vegetative and reproductive allocation analysis. PROC CORR (SAS ver. 8.02) was used to generate (co)variance matrices, after culling plants with missing data. We then employed Flury's hierarchical common principal components (CPC) analysis, using a jump-up approach (Phillips and Arnold 1999), to test for significant differences between (co)variance matrices. The test statistic for each level of the hierarchy is a $\chi^{2}$ likelihood, with degrees of freedom from the underlying levels. CPCrand, a randomization test of the CPC hierarchy, was also used to ensure that significant results were not due to lack of normality in the data (Phillips and Arnold 1999). Note that the reproductive matrix and the reproductive and vegetative matrix were tested separately to facilitate significance testing and to determine the origin of significant matrix differences, that is, whether correlations among reproductive traits differed significantly between the sexes independent of vegetative traits. In addition to this multivariate CPC approach, we used Fisher's Z-tests to test for the significance of specific bivariate correlations, that is, possible sources of significant differences in multivariate matrices.

\section{Results}

\section{Sex and Treatment Effects}

In a MANOVA, vegetative and reproductive traits were significantly influenced by the effect of sex (Wilks's $\lambda, F_{10,66}=$ 58.02, $P<0.0001$ ) and light treatment (Wilks's $\lambda, F_{10,66}=$ $2.29, P=0.0227)$; however, these traits did not vary with the sex by treatment interaction (Wilks's $\lambda, F_{10,66}=1.02, P=$ 0.43). In subsequent univariate ANOVAs, significant effects of sex were found for petal claw length, corolla diameter, filament length, anther length, and ovule size (table 1). Flowers from hermaphrodites had significantly longer petal claws, greater corolla diameters, and longer filaments and anthers compared with flowers from females (fig. 1A). In contrast, flowers from females had larger ovules (fig. $1 B$ ) than did those from hermaphrodites. The sexes did not differ significantly in ovule number per locule (fig. 1C).

Significant sex $\times$ treatment interactions were found for petal claw length, ovary width, length at internode 2 , and flower

\section{Table 1}

Mean Squares (MS) and Degrees of Freedom (df) from an ANOVA for Effects of Sex, Light Treatment, and Sex $\times$ Treatment Interactions on Vegetative and Floral Traits of Silene vulgaris

\begin{tabular}{lccccc}
\hline & Sex & Light treatment & Sex $\times$ light treatment & Error df & Error MS \\
\hline log10 (flower no.) & .000 & .004 & $.584^{*}$ & 87 & .112 \\
Calyx length & 8.16 & .31 & .09 & 85 & 2.60 \\
Petal claw length & $11.92^{* * *}$ & $9.78^{* *}$ & $10.86^{*}$ & 85 & 2.09 \\
Corolla diameter & $152.50^{* * * *}$ & .51 & .09 & 85 & 4.44 \\
Filament length & $2031.64^{* * *}$ & 7.70 & .24 & 85 & 5.68 \\
Anther length & $21.61^{* * *}$ & .05 & .13 & 85 & .14 \\
Ovary width & .48 & .36 & $.81^{* * *}$ & 85 & .19 \\
Ovule size & $.006^{* * *}$ & .001 & .002 & 75 & .001 \\
Ovules per locule & 9.55 & 45.79 & 40.93 & 84 & 89.83 \\
Internode 2 & .44 & $7.18^{* * *}$ & $3.73^{*}$ & 87 & .60 \\
\hline
\end{tabular}

Note. Internode 2 is the combined length of the first two internodes.

$* P \leq 0.05$.

${ }^{* *} P \leq 0.01$ 


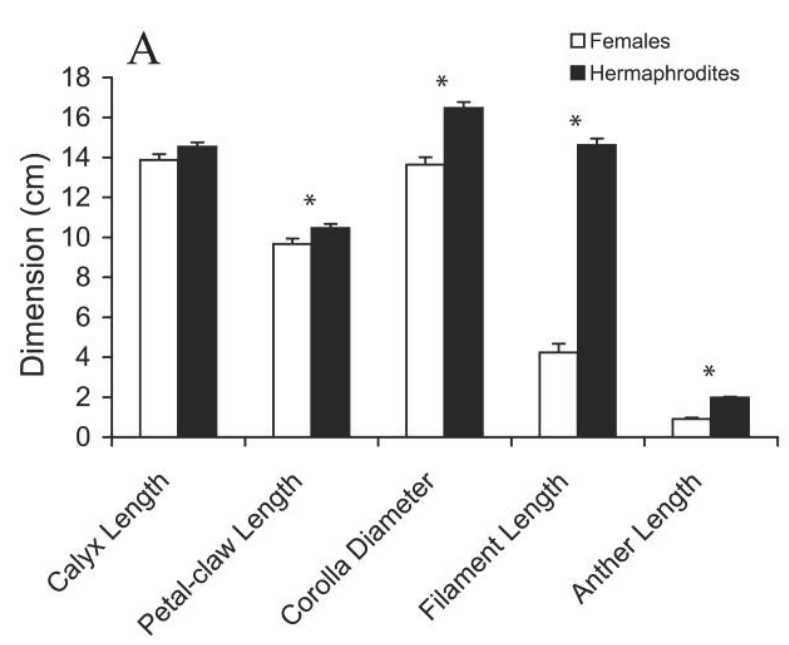

number, but hermaphrodites did not (fig. 3B). Moreover, Fisher's $Z$-test indicates that the anther length-ovule size correlation $(Z$ score $=2.944, P<0.01)$ is significantly different between females and hermaphrodites, as is the ovule size-number correlation $(Z$ score $=2.448, P<0.05)$. Hierarchical CPC analysis indicates the two reproductive allocation $\mathbf{P}$ matrices are unrelated and do not share the first principal component (CPC1, $\left.\chi^{2}=8.63, \mathrm{df}=2, P=0.0134\right)$. This interpretation of matrices is also supported by randomization tests (CPC1, $P=0.0198)$.

The floral display matrix (table 3 ) indicates significant positive correlations between calyx length and petal claw length, between calyx length and corolla diameter, and between petal claw length and filament length in hermaphrodites. In contrast, the only significant correlation in female flowers was petal claw length to filament length, and there was also a marginally significant negative correlation between flower number and filament length $(P=0.072)$. However, Fisher's $Z$-test did not indicate significant differences in correlations between females and hermaphrodites (although the calyx length to petal claw length correlation difference was marginally significant; $P=0.057$ ). Hierarchical CPC analysis indicates that the two display $\mathbf{P}$ matrices differ at the level of proportionality (proportionality, $\chi^{2}=$ 41.45, $\mathrm{df}=14, P=0.0002$ ), a result supported by CPCrand (proportionality, $P=0.0217$ ). This hierarchical analysis suggests that the two $\mathbf{P}$ matrices share common principal components but differ in scale.

Hermaphrodites in foliar shade exhibited a significant negative correlation between length at internode 2 and ovule number per locule, whereas females in foliar shade exhibited a marginally significant $(P=0.087)$ positive correlation between these two traits (table 4; fig. 3C). Fisher's Z-test indicates that the length at internode 2-ovule number correlation differs significantly between females and hermaphrodites growing in foliar shade conditions $(Z$ score $=2.763, P<0.01)$. Flury's CPC test likewise indicated that the (co)variance matrix of females in foliar shade differed from the matrix of hermaphrodites in foliar shade (CPC1, $\left.\chi^{2}=12.832, \mathrm{df}=3, P=0.005\right)$, an analysis that was also supported by the CPC randomization procedure (CPC1, $P<0.0112$ ). Hermaphrodites in full sun did not exhibit significant correlations between any of the vegetative or reproductive traits tested (table 4). Neither Fisher's nor Flury's test detected any significant differences in vegetative-reproductive correlations between hermaphrodites raised in foliar shade versus full sun.

\section{Discussion}

Consistent with many other studies, our results revealed significant sexual dimorphism in individual floral traits of Silene vulgaris. As would be expected on the basis of functional gender, flowers on hermaphrodites had longer anthers and filaments but smaller ovules compared with those on females. In addition to these differences in the expression of individual traits, we observed several sex-specific trade-offs. Females exhibited a classic size-number trade-off, whereas hermaphrodites showed a trade-off between allocation to anther versus ovule size. Although females elongated internodes more in response to simulated foliar shade than did hermaphrodites, the increase in vegetative allocation came at the cost of ovule number only 

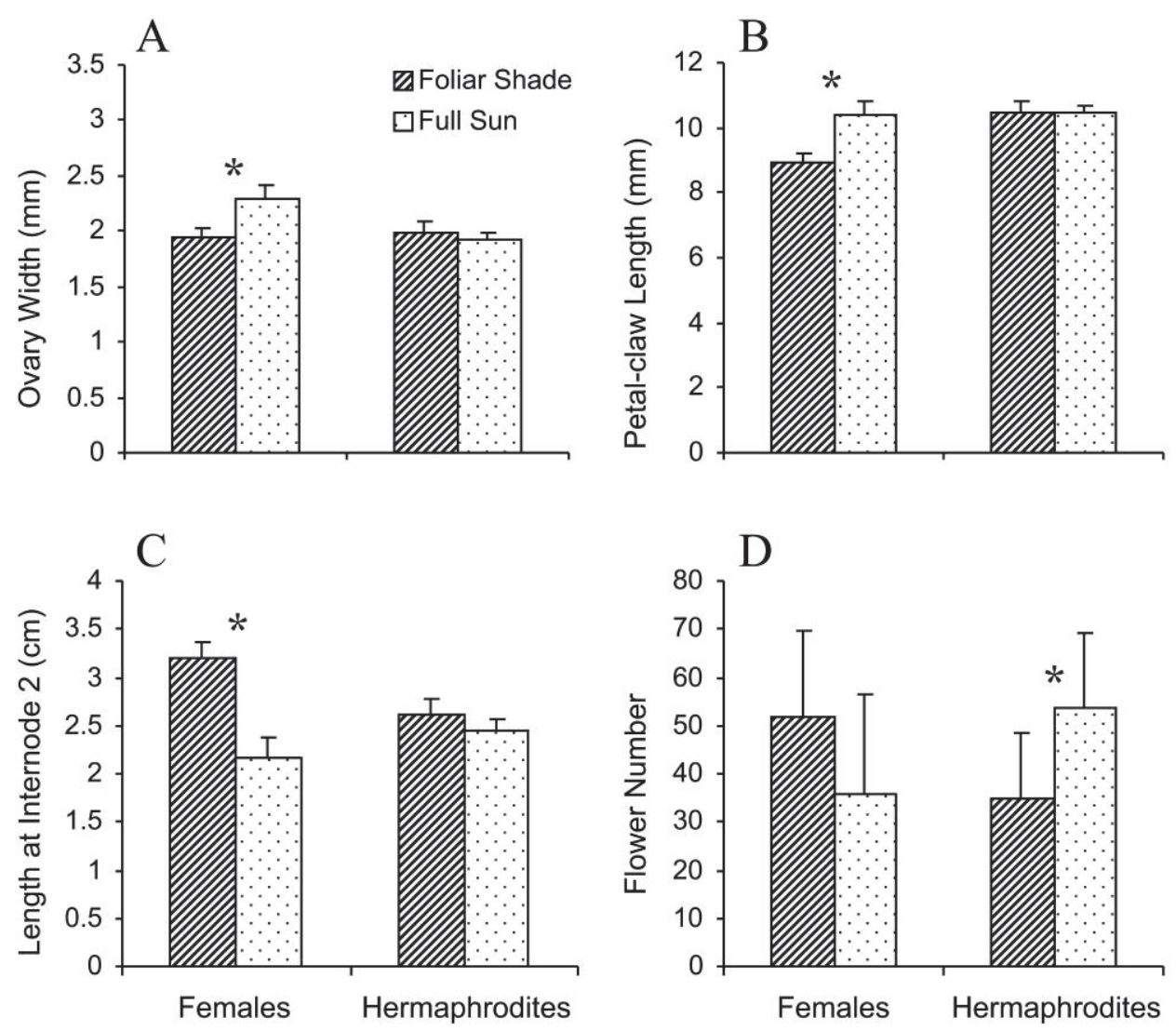

Fig. 2 Bar graphs of significant sex $\times$ treatment effects. Asterisks indicate significant differences $(P \leq 0.05)$. Least squares means \pm 1 SE are shown for ovary width $(A)$, petal claw length $(B)$, and length of first two internodes $(C)$. Least squares means and $95 \%$ confidence intervals are shown for back-transformed flower number $(D)$.

in hermaphrodites. Of particular evolutionary relevance, hermaphrodites would be expected to become increasingly male and the species increasingly sexually dimorphic as a consequence of the observed trade-offs. Below, we further discuss the observed patterns of sexual dimorphism (in individual traits and in phenotypic integration) and the selective and genetic mechanisms potentially underlying this dimorphism.

Given differences in functional gender between females and hermaphrodites, we expected floral display to differ between the sexes, with hermphrodites potentially having larger diplays. Flowers on hermaphrodites, in fact, had longer petals and wider corollas than flowers produced by females (fig. 1), providing hermaphrodites with a larger floral display compared with females. These data are consistent with other studies reporting larger flower size in hermaphrodites in this species as well as other gynodioecious species (Dulberger and Horovitz 1984; Delph 1996; Eckhart 1999; Ashman 2003; Asikainen and Mutikainen 2005; Olson et al. 2005; Beaumont et al. 2006; Delph et al. 2006). Various hypotheses have been proposed for why flowers on hermaphrodites might be larger than those on females (Delph 1996; Delph et al. 1996). These hypotheses include pleiotropic effects of hormones produced by pollen, that the petals enclose and protect developing reproductive parts in buds (which are larger in hermaphrodites as a consequence of developing anthers), and selection on hermaphrodites for enhanced siring success (Bell 1985). Exploring the causal basis of these hypotheses is easier said than done. Nevertheless, using pollen removal as a proxy for siring success, Ashman and Diefenderfer (2001) showed consistent selection for larger petal size among hermaphrodites in a gynodioecious strawberry under varying environmental conditions. This lends credence to

Table 2

\section{Bivariate Correlation Matrices for Reproductive Allocation} in Female and Hermaphroditic plants of Silene vulgaris

\begin{tabular}{lccc}
\hline & Anther length & Ovule size & Ovule no. \\
\hline Female: & & & \\
Anther length & $\ldots$ & $.26^{*}$ & -.19 \\
Ovule size & & $\ldots$ & $-.49^{*, * * *}$ \\
Ovule no. & & & $\ldots$ \\
Hermaphrodite: & $\ldots$ & $-.42^{*, * *}$ & .11 \\
Anther length & $\ldots$ & $\ldots$ & $.06^{* *}$ \\
Ovule size & & & $\ldots$ \\
Ovule no. & & & $\ldots$ \\
\hline
\end{tabular}

* Fisher's Z-test comparing correlation coefficients between females and hermaphrodites differed at $P \leq 0.05$.

** Bivariate correlations differed significantly from 0 at $P \leq 0.01$. 

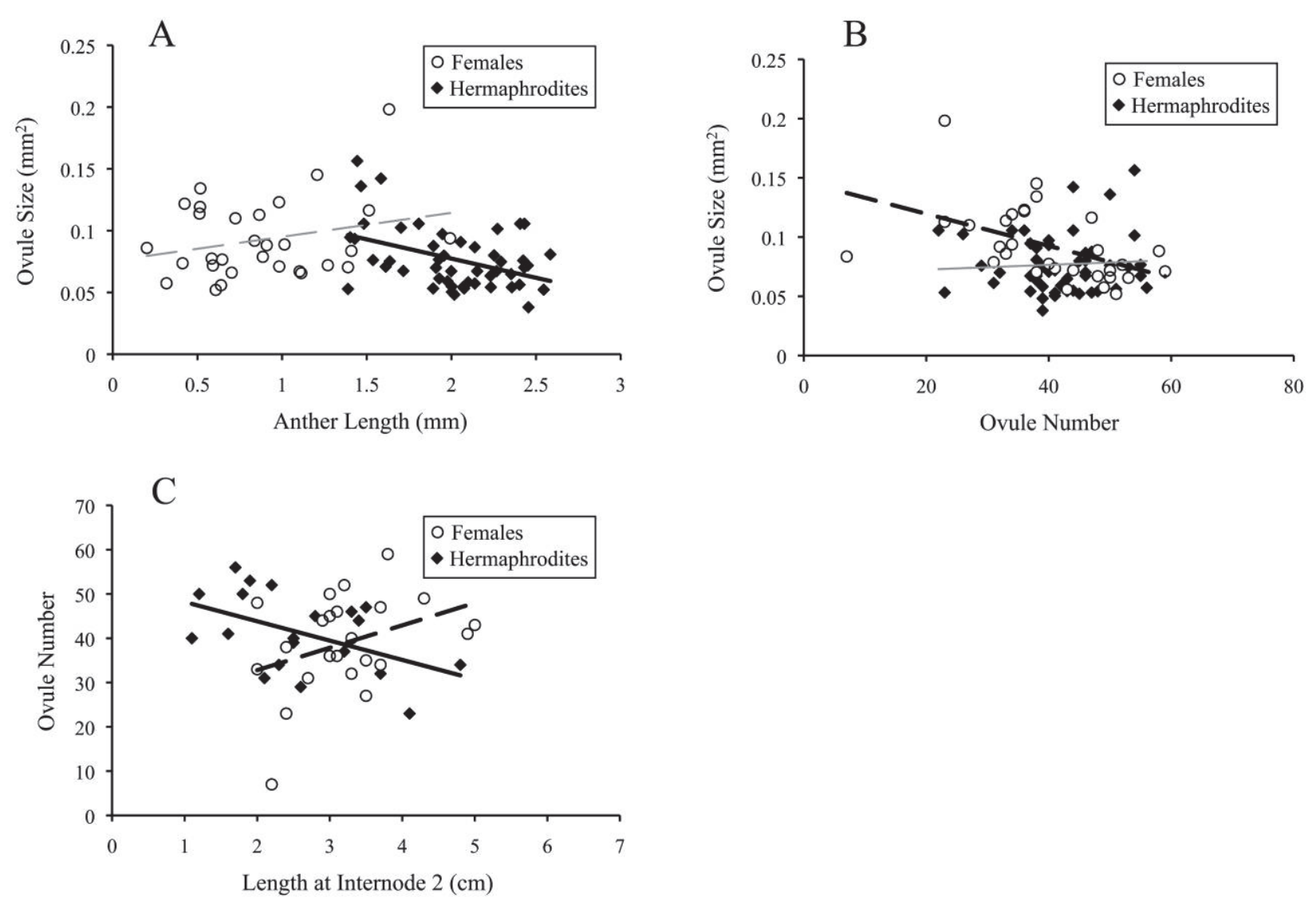

Fig. 3 Phenotypic correlations between hermaphrodite (diamonds, solid lines) and female (circles, dashed lines) plants of Silene vulgaris for anther length and ovule size across both light environments $(A)$, ovule number and ovule size across both light environments $(B)$, and length at internode 2 and ovule number in the foliar shade environment $(C)$. Significant correlations are indicated by black lines, and nonsignificant trends are denoted by gray lines.

the hypothesis that hermaphrodites have larger flowers as a consequence of sexual selection by way of male function.

Differences in functional gender and attendant selection could also result in sexual dimorphism in floral trait integration; we observed weak evidence for this prediction. For floral traits, sex $\times$ treatment interactions were significant only for petal claw length, ovary width, and total flower number (fig. 2; table 1), indicating that females and hermaphrodites differ little in their responses to the light environment. Nevertheless, females reduced the length of their petal claws under light-limited conditions, but hermaphrodites did not. This sex-specific responsiveness could be interpreted as a product of selection on male function in hermaphrodites: if the placement of anthers at the top of the petal claws has a large effect on pollen removal, then selection may have favored hermaphrodites that do not plastically alter their petal claw length (or their filament length). Consistent with the lack of sex $\times$ treatment interactions, the display matrix indicates that there are only qualitatively stronger correlations (rather than quantitative differences based on Fisher's Z-tests; table 3) between floral organs in hermaphrodites as compared with females. The significant correlations observed in flowers on hermaphrodites (between calyx length and petal claw length, between calyx length and corolla diameter, and between petal claw length and filament length) may benefit male function by positioning petals and calyces to enhance floral display and by positioning anthers to facilitate pollen removal (Conner and Via 1993; Anderson and Busch 2006). Alternatively, the observed positive correlations may be the result of pleiotropic effects on developmentally related traits (Conner 2002; Juenger et al. 2005). Consistent with this latter view, both females and hermaphrodites exhibit a positive correlation between petal claw length and filament length, and elements of the correlation matrices were not significantly different between the sexes.

We found correlations between pairs of reproductive traits and between reproductive and vegetative traits, many of which were consistent with predicted trade-offs between male and female function and life-history traits (progeny size vs. number). Our analysis of reproductive allocation (table 2) suggests that females experience a trade-off between ovule size and ovule number, while hermaphrodites experience a trade-off between ovule size and anther length. Although we estimated phenotypic rather than genotypic correlations, the observed negative correlations are likely to reflect genetically based trade-offs rather than environmental covariances because variation in plant vigor, resulting from heterogeneity in environmental qual- 
Table 3

\begin{tabular}{lccccc}
\multicolumn{5}{c}{$\begin{array}{c}\text { Bivariate Correlation Matrices for Floral Display in } \\
\text { Females and Hermaphrodites of Silene vulgaris }\end{array}$} \\
$\begin{array}{l}\text { Flower } \\
\text { no. }\end{array}$ & $\begin{array}{c}\text { Calyx } \\
\text { length }\end{array}$ & $\begin{array}{c}\text { Petal } \\
\text { claw } \\
\text { length }\end{array}$ & $\begin{array}{c}\text { Corolla } \\
\text { diameter }\end{array}$ & $\begin{array}{c}\text { Filament } \\
\text { length }\end{array}$ \\
\hline & & & & & \\
\hline Female: & $\ldots$ & -.24 & .08 & -.24 & -.37 \\
Flower no. & & $\ldots$ & .17 & .05 & .3 \\
Calyx length & & & $\ldots$ & -.16 & $.43^{*}$ \\
Petal claw length & & & & $\ldots$ & .15 \\
Corolla diameter & & & & & $\ldots$ \\
Filament length & & & & & $\ldots$ \\
Hermaphrodite: & & -.19 & -.09 & -.2 & -.26 \\
Flower no. & $\ldots$ & $\ldots$ & $.66^{* * *}$ & $.56^{* * *}$ & .38 \\
Calyx length & & $\ldots$ & $\ldots$ & .25 & $.46^{*}$ \\
$\begin{array}{l}\text { Petal claw length } \\
\text { Corolla diameter }\end{array}$ & & & & $\ldots$ & .03 \\
Filament length & & & & & $\ldots$ \\
\hline
\end{tabular}

$* P \leq 0.05$ (significance for bivariate correlations).

** $P \leq 0.01$ (significance for bivariate correlations).

ity, typically enhances allocation to multiple functions and thereby generates a positive rather than negative correlation between pairs of traits. Specifically, in reference to the current experiment, none of these traits (ovule size, ovule number, or anther size) exhibited a significant treatment effect or sex $x$ treatment interaction (table 1), suggesting that these are genetically fixed trade-offs. The observed ovule size-number trade-off indicated by our results is consistent with progeny size-number trade-offs predicted under life-history theory but is rarely reported by empirical studies (Greenway and Harder 2007), although some studies have shown a negative correlation between seed size and ovule number (Lalonde and Roitberg 1989; Lehtilä and Ehrlén 2005). Not surprisingly, females do not seem to experience a trade-off between anther and ovule production, as would be expected given that females derive fitness exclusively through female function and have presumably experienced (and apparently responded to) past selection to minimize allocation to vestigial stamens.

The vegetative trait, internode elongation, responded plastically to foliar shade, as expected (Smith and Whitelam 1997), and allocation to this function was significantly correlated with reproductive function in both sexes (fig. 3C). Although stem elongation comes at the cost of allocation to roots and leaves, this carbon investment is recouped in high-density settings as plants overtop neighbors and thereby increase lifetime light interception (Dudley and Schmitt 1996; Donohue and Schmitt 1999; Weinig 2000). One might predict a priori that sexes would exhibit similar elongation responses, given the benefits to either sex of higher light interception. However, we observed a significant sex $\times$ treatment interaction for internode length, with females exhibiting greater internode elongation in response to the foliar shade treatment compared with hermaphrodites (fig. 2C). Females also exhibited a positive correlation between internode length and ovule number (fig. $3 C)$ possibly because of variation in vigor among individuals, whereby large individuals have both long internodes and many ovules and small individuals have short internodes and few ovules. In contrast, hermaphrodites showed a significant negative correlation between internode elongation and ovule number when grown in foliar shade. This trade-off is consistent with evolutionary forces leading hermaphrodites to specialize on male function in the presence of females (Charlesworth and Charlesworth 1978), such that they sacrifice female rather than male function when faced with resource limitation. Similar results were shown in Hebe subalpina following resource limitation created by shoot defoliation: hermaphrodites reduced their fruit set but not growth, whereas females did the opposite (Delph 1990).

In sum, the results were largely consistent with predicted sexual dimorphism in individual traits and trait correlations in gynodioecious species for many, but not all, floral and vegetative traits. For example, while hermaphrodites exhibited a trade-off between vegetative growth and ovule number per flower, they were otherwise insensitive to the foliar shade treatment and failed to plastically reduce allocation to female function at the per flower level (i.e., the sex $\times$ treatment interactions were nonsignificant for ovule number and size). These results reveal that the hermaphrodites of $S$. vulgaris do not alter their withinflower allocation to male versus female function in response to variation in the light regime. However, the larger size of floral "display" traits in hermaphrodites compared with those in females, the qualitatively stronger correlations between display traits in hermaphrodites compared with females, and the appar-

Table 4

Bivariate Correlation Matrices for Vegetative and Reproductive Traits among Females and Hermaphrodites Raised under Full Sun and Simulated Foliar Shade Light Treatments

\begin{tabular}{cccc}
\hline Length at & Anther & Ovule & Ovule \\
internode 2 & length & size & no. \\
\hline
\end{tabular}

Female:

Foliar shade:

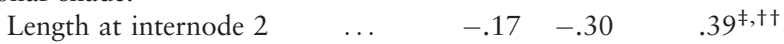

$\begin{array}{llll}\text { Anther length } & \ldots & .19^{\dagger} & -.19\end{array}$

Ovule size

Ovule no.

Hermaphrodite:

Foliar shade:

$\begin{array}{lllll}\text { Length at internode } 2 & \ldots & .13 & .01 & -.50 " \text {, } \dagger+\end{array}$

Anther length

Ovule size

Ovule no.

Full sun:

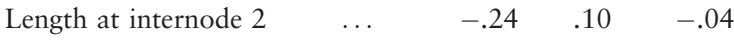

Anther length

$\begin{array}{lll}\cdots & -.31 \quad .13\end{array}$

Ovule size

.01

Ovule no.

Note. Because of low sample size, females grown under full sun were dropped from this comparison.

${ }^{\ddagger} P=0.087$ (significance for bivariate correlations).

$* P \leq 0.05$ (significance for bivariate correlations).

${ }^{* *} P \leq 0.01$ (significance for bivariate correlations).

${ }^{\dagger} P \leq 0.05$ (signficance of Fisher's $Z$-test comparing females and hermaphrodites in foliar shade).

${ }^{\dagger \dagger} P \leq 0.01$ (significance of Fisher's $Z$-test comparing females and hermaphrodites in foliar shade). 
ent trade-offs between anther size and ovule size as well as elongation and ovule number in hermaphrodites are consistent with theory suggesting that male function contributes more to the fitness of hermaphrodites than does female function in gynodioecious species (Lloyd 1976). More generally, the results provide a rare empirical example of trade-offs between reproductive and vegetative function and of widely predicted (but rarely observed) size-number trade-offs (Stearns 1992).

\section{Acknowledgments}

We thank Pam Warnke for assisting in the care of greenhouse facilities and plants and Jennifer Dechaine, Charles Willis, and Eric Boehlke for aid in planting and maintaining experimental plants. This research was supported by National Science Foundation grants DBI-0227103 and DBI-0605736 to C. Weinig.

\section{Literature Cited}

Anderson IA, JW Busch 2006 Relaxed pollinator-mediated selection weakens floral integration in self-compatible taxa of Leavenworthia (Brassicaceae). Am J Bot 93:860-867.

Ashman T-L 2003 Constraints on the evolution of males and sexual dimorphism: field estimates of genetic architecture of reproductive traits in three populations of gynodioecious Fragaria virginiana. Evolution 57:2012-2025.

Ashman T-L, C Diefenderfer 2001 Sex ratio represents a unique context for selection on attractive traits: consequences for the evolution of sexual dimorphism. Am Nat 157:334-347.

Ashman T-L, L Penet 2007 Direct and indirect effects of a sex-biased antagonist on male and female fertility: consequences for reproductive trait evolution in a gender-dimorphic plant. Am Nat 169: 595-608.

Asikainen E, P Mutikainen 2005 Preferences of pollinators and herbivores in gynodioecious Geranium sylvaticum. Ann Bot 95:879886.

Ballaré CL, AL Scopel, RA Sanchez 1990 Far-red radiation reflected from adjacent leaves an early signal of competition in plant canopies. Science 247:329-332.

Beaumont AJ, TJ Edwards, FR Smith 2006 The first record of gynodioecy in a species of Gnidia (Thymelaeaceae) from South Africa. Biol J Linn Soc 152:219-233.

Bell G 1985 On the function of flowers. Proc R Soc B 224:223-265.

Brock MT, C Weinig 2007 Plasticity and environment-specific covariances: an investigation of floral-vegetative and within flower correlations. Evolution 61:2913-2924.

Charlesworth B, D Charlesworth 1978 A model for the evolution of dioecy and gynodioecy. Am Nat 112:975-997.

Conner JK 2002 Genetic mechanisms of floral trait correlations in a natural population. Nature 420:407-410.

Conner JK, A Sterling 1995 Testing hypotheses of functional relationships: a comparative survey of correlation patterns among floral traits in five insect-pollinated plants. Am J Bot 82:1399-1406.

Conner JK, S Via 1993 Patterns of phenotypic and genetic correlations among morphological and life-history traits in wild radish, Raphanus raphanistrum. Evolution 47:704-711.

Delph LF 1990 Sex-differential resource allocation patterns in the subdioecious shrub Hebe subalpina. Ecology 71:1342-1351.

1996 Flower size dimorphism in plants with unisexual flowers. Pages 217-238 in DG Lloyd, SCH Barrett, eds. Floral biology. Chapman \& Hall, New York.

Delph LF, T-L Ashman 2006 Trait selection in flowering plants: how does sexual selection contribute? Integr Comp Biol 46:465-472.

Delph LF, LF Galloway, ML Stanton 1996 Sexual dimorphism in flower size. Am Nat 148:299-320.

Delph LF, CM Lively, CJ Webb 2006 Gynodioecy in native New Zealand Gaultheria (Ericaceae). N Z J Bot 44:415-420.

Delph LF, DG Lloyd 1991 Environmental and genetic control of gender in the dimorphic shrub Hebe subalpina. Evolution 45: 1957-1964.
Delph LF, DE Wolf 2005 Evolutionary consequences of gender plasticity in genetically dimorphic breeding systems. New Phytol 166:119-128.

Donohue K, J Schmitt 1999 The genetic architecture of plasticity to density in Impatiens capensis. Evolution 53:1377-1386.

Dudley SA, J Schmitt 1996 Testing the adaptive plasticity hypothesis: density-dependent selection on manipulated stem length in Impatiens capensis. Am Nat 147:445-465.

Dulberger R, A Horovitz 1984 Gender polymorphism in flowers of Silene vulgaris (Moench) Garcke (Caryophyllaceae). Biol J Linn Soc 89:101-117.

Eckhart VM 1999 Sexual dimorphism in flowers and inflorescences. Pages 123-148 in MA Geber, TE Dawson, LF Delph, eds. Gender and sexual dimorphism in flowering plants. Springer, Berlin.

Greenway CA, LD Harder 2007 Variation in ovule and seed size and associated size-number trade-offs in angiosperms. Am J Bot 94: 840-846.

Hillesheim E, SC Stearns 1992 Correlated responses in life history traits to artificial selection for body weight in Drosophila melanogaster. Evolution 46:745-752.

Juenger T, JM Pérez-Pérez, S Bernal, JL Micol 2005 Quantitative trait loci mapping of floral and leaf morphology traits in Arabidopsis thaliana: evidence for modular genetic architecture. Evol Dev 7:259_ 271.

Lalonde RG, BD Roitberg 1989 Resource limitation and offspring size and number trade-offs in Cirsium arvense (Asteraceae). Am J Bot 76:1107-1113.

Lehtilä K, J Ehrlén 2005 Seed size as an indicator of seed quality: a case study of Primula veris. Acta Oecol 28:207-212.

Lloyd DG 1976 The transmission of genes via pollen and ovules in gynodioecious angiosperms. Theor Popul Biol 9:299-316.

Maliakal SK, K McDonnell, SA Dudley, and J Schmitt 1999 Effects of red to far-red ratio and plant density on biomass allocation and gas exchange in Impatiens capensis. Int J Plant Sci 160:723733.

Morgan DC, H Smith 1979 A systematic relationship between phytochrome-controlled development and species habitat, for plants grown in simulated natural radiation. Planta 145:253-258.

Olson MS, DE McCauley, D Taylor 2005 Genetics and adaptation in structured populations: sex ratio evolution in Silene vulgaris. Genetica 123:49-62.

Phillips PC, SJ Arnold 1999 Hierarchical comparisons of genetic variance-covariance matrices. I. Using the Flury hierarchy. Evolution 53:1506-1515.

Pigliucci M 2003 Phenotypic integration: studying the ecology and evolution of complex phenotypes. Ecol Lett 6:265-272.

Shykoff JA, SO Kolokotronis, CL Collin, M López-Villavicencio 2003 Effects of male sterility on reproductive traits in gynodioecious plants: a meta-analysis. Oecologia 135:1-9.

Smith H 1982 Light quality, photoperception, and plant strategy. Annu Rev Plant Physiol 33:481-518. 
2000 Phytochromes and light signal perception by plants: an emerging synthesis. Nature 407:585-591.

Smith H, GC Whitelam 1997 The shade avoidance syndrome: multiple responses mediated by multiple phytochromes. Plant Cell Environ 20:840-844.
Stearns SC 1992 The evolution of life histories. Oxford University Press, Oxford. 249 pp.

Weinig C 2000 Differing selection in alternative competitive environments: shade-avoidance responses and germination timing. Evolution 54:124-136. 